\title{
A Comparison of therapeutic strategies consisting of different combinations of surgery and/or radiotherapy in Pulmonary MALT-MZL: A population-based Analysis of SEER Data, 1992-2013
}

Xinyi Du

Jiangsu Province Hospital and Nanjing Medical University First Affiliated Hospital

Lin Quan

Nanjing Chest Hospital

Yi Miao

Jiangsu Province Hospital and Nanjing Medical University First Affiliated Hospital

Lei Cao

Jiangsu Province Hospital and Nanjing Medical University First Affiliated Hospital

Rong Huang

Jiangsu Province Hospital and Nanjing Medical University First Affiliated Hospital

Hailing Liu

Jiangsu Province Hospital and Nanjing Medical University First Affiliated Hospital

Lei Fan ( $\nabla$ fanlei3014@126.com )

Jiangsu Province Hospital and Nanjing Medical University First Affiliated Hospital https://orcid.org/00000002-9368-4987

Wei Xu

Jiangsu Province Hospital and Nanjing Medical University First Affiliated Hospital

Jianyong Li

Jiangsu Province Hospital and Nanjing Medical University First Affiliated Hospital

\section{Research article}

Keywords: Pulmonary MALT lymphoma, Surgery, Radiation, SEER

Posted Date: August 18th, 2020

DOI: https://doi.org/10.21203/rs.3.rs-50136/v1

License: () (i) This work is licensed under a Creative Commons Attribution 4.0 International License. Read Full License 


\section{Abstract \\ Background}

Pulmonary marginal zone B-cell lymphoma of the mucosa-associated lymphoid tissue type (MALT) is recognized as the most common type of primary pulmonary lymphomas. However, due to its relatively-low proportion, the studies focused on this patient population were limited. We aimed to reveal the status of surgery and radiotherapy in survival of pulmonary MALT lymphoma patients.

\section{Methods}

A retrospective analysis was conducted on patients who were pathologically diagnosed as pulmonary MALT lymphoma between 1992 and 2013. Their treatment information was collected in Surveillance, Epidemiology, and End Results (SEER) database. According to the different treatments, they were divided into four groups: Both Surgery and Radiation(SR), Surgery(S), Radiation(R) and No Surgery Or Radiation(NSR). The further subgroup analyses were performed according to age of onset and clinical stages. Overall survival (OS) was calculated from diagnosis up to the date of death or the last follow-up of each patient. Survival curves constructed by the Kaplan-Meier method and log-rank test were utilized for comparison.

\section{Results}

There were 860 pulmonary MALT lymphoma patients were enrolled. The median OS was 55.0 months (0256.0 months). The OS between patients who underwent surgery and/or radiotherapy(S/R/SR) or not(NSR) (473 VS 387) had shown a significant difference of each other $(P<0.0001)$, so did the comparison among the four subgroups(SR VS S VS R VS NSR, $P<0.0001)$. Although there wasn't any statistical difference in the OS between $S R$ and $S$ groups $(P=0.1174)$, further analysis on the causes of death revealed that, additional radiation therapy may lead to good short-term efficacy, while elevated mortality associated with long-term pulmonary complications was noteworthy. In the subgroup analyses, patients in stage I-II and over 60 years old shared similar trends with total population involved in the study $(P=0.0001 ; P<0.0001)$.

\section{Conclusions}

The present study confirmed the value of surgery and the possible effects of radiotherapy among patients with pulmonary MALT lymphoma by clinical data from a large number of samples. If the improved radiotherapy regimens are chosen or the pulmonary complications caused by radiotherapy are wellmanaged, chances will be high that extra benefits could be achieved by combining radiotherapy with the surgical-based therapy.

\section{Background}


Extranodal mucosa-associated lymphoid tissue lymphoma (MALT) lymphoma is an independent subtype of low-grade B-cell lymphoma which comprises $7-8 \%$ of all B-cell lymphomas. Primary pulmonary MALT lymphoma is recognized as the predominant pathological type in primary pulmonary lymphoma, roughly $90 \%$. Lung (8-9\%) is one of the relatively-rare sites of MALT lymphoma, less common than other anatomic sites, such as stomach (35\%), parotid and salivary glands (18-26\%), skin (12-26\%), eyes and ocular adnexa $(7-12 \%)^{[1,2]}$. So far, the standard first-line treatment regimens for pulmonary MALT lymphoma haven't been established. Radiotherapy, surgery, antibiotic therapy, systemic chemotherapy and/or immunotherapy or even "watch and wait" strategies were considered to be treatment options. In general, involved-site radiation therapy (ISRT) is preferred and widely used as the primary treatment for patients in early stages with focal lesions, while for advanced stage patients with treatment indications, systemic immunochemotherapy is recommended. However, the role of surgery and optional initial treatment is still controversial till now. In this study, survival analysis was conducted among different treatment combinations of surgery and/or radiation to evaluate their clinical applications.

\section{Methods}

From March 1992 to December 2013, totally 860 patients with a diagnosis of pulmonary MALT lymphoma whose treatment information was recorded into Surveillance, Epidemiology, and End Results (SEER) were enrolled in the study. They all went through a histology diagnostic confirmation. According to WHO Classification of Tumours of Haematopoietic and Lymphoid Tissues, their diagnoses were made. All patients were under active follow-up.

\section{Data collection and follow-up}

The SEER-collected clinical data of pulmonary MALT lymphoma patients used in this research mainly consisted of two parts, one was baseline information including age, gender, Ann Arbor stage, primary site(Table1A), and the other part was survival information such as survival condition, survival months, cause of death and first-course treatment.The distribution of the four subgroups were shown by the pie chart(Figure1B). This research mainly discussed the surgical intervention and radiotherapy. Depending on the different treatment options of surgery and/or radiation they received, these pulmonary MALT lymphoma patients were classified into four groups: Both Surgery And Radiation (SR, $n=21)$, Surgery $(S, n=391)$, Radiation ( $R, n=61)$ and No Surgery Or Radiation (NSR, $n=387$ ). The overall survival (OS) time is defined as the period from diagnosis to death or last follow-up which was up to December 2013.

\section{Statistical Analysis}

Statistical analysis was performed by SPSS 21.0, GraphPad Prism 6.0 and Microsoft Office 2010 software. To estimate the impact of different therapies on patients among groups, survival curves were constructed using Kaplan-Meier method and log-rank test was used for comparisons between groups. The definition of statistically significance was established at $\mathrm{P} \leq 0.05$.

\section{Results}




\section{Patients' characteristics}

There were 860 cases of pulmonary MALT lymphoma with positive evidence of histopathology, which approximately accounted for $5.0 \%$ of all MALT lymphoma patients $(\mathrm{N}=17343)$ documented in SEER database between March 1992 to December 2013. There were 356(41.4\%) male patients and the rest $504(58.6 \%)$ were females, the median age was 66 years old(19-93) at diagnosis. According to Ann Arbor staging system, the number of these patients were 636(74.0\%) in early stages (I-II) and 224(26\%) in advanced stages (III-IV) respectively. The primary sites of lung were various among all the pulmonary MALT lymphoma patients, including $245(28.5 \%)$ cases of which were in the upper lobe, $100(11.6 \%)$ in the middle lobe, $256(29.8 \%)$ in the lower lobe, $20(2.3 \%)$ cases of which were with overlapping lesion of lung, and the remaining $239(27.8 \%)$ cases classified into Lung NOS. As for the laterality of lesions, $722(84.0 \%)$ patients were mainly with unilateral lesions at diagnosis. All patients were grouped into four groups in accordance with different treatment measures: SR $(21,2.4 \%)$, S (391, 45.5\%), R (61, 7.1\%) and NSR (387, 45.0\%). Baseline clinical features of each group were listed in Table1.

\section{Survival analysis}

The median follow-up of the 860 patients was 55(0-256) months. Statistics analysis revealed that the difference in OS was significant among the four groups in which patients treated in different ways $(P<0.0001$,Figure2A), their median survival were unreached for SR group, 165months for $S$ group, 119 moths for $\mathrm{R}$ and 120 months for NSR respectively. The OS of four groups were compared in pairs, and $\mathrm{P}$ values were listed in Table2B. The 5-year and 10 year cumulative survival rate were $82.57 \%$ and $73.88 \%$. In total, $249(29.0 \%)$ patients died during the period of follow-up, the causes of death were summarized as Figure3A.

The leading causes of death among all patients enrolled in the study were related to non-hodgkin lymphoma $(n=64,25.7 \%)$, cardiovascular and cerebrovascular diseases $(n=47,18.9 \%)$ and pulmonary disease $(n=45,18.1 \%)$. In addition, the constitution of causes of death among the patients who received radiotherapy was listed in Table3B. The main cause of death in patients treated with radiotherapy was pulmonary-related diseases $(6 / 15,40.0 \%)$, and that proportion is about twice that of the whole population in the study.

\section{Subgroup analyses}

To further clarify the relationship between the OS and different treatment methods that patients received, subgroup analyses were conducted among patients of different ages of onset and clinical stages.

\section{Age}

Notable differences were seen between patients over 60 years old and those under 60 years old, and the OS of elderly patients $(\geq 60)$ were significantly inferior to those who were younger than $60(P<0.0001$,Figure4A). Four treatment methods were further analyzed in two subgroups divided according to age, and there was a statistically significant difference in elderly group $(\geq 60, P=0.0001$, Figure4B) while not in the younger one $(<60, P=0.3639$, Figure4C). The older participants(elderly group, $\geq 60)$ underwent both surgery and radiation exhibited a definite survival advantage compared with the other three treatment groups. While in 
the younger group $(<60)$, from the perspective of survival curve, the survival difference caused by four different treatments was not apparent.

\section{Clinical stage}

Although the survival curves constructed between early-(Stage I-II)and advanced-(Stage III-IV)stage patients showed no difference in survival $(P=0.0638$,Figure4D), due to the various treatments recommended for patients with different clinical stages, subgroup analyses were still performed for the four kinds of treatments in patients with Stage I-II and III-IV. In the term of survival curves, patients with stage I-II shared similar trends with total population involved in the study $(\mathrm{P}<0.0001$,Figure4E). As for patients in stage III-IV, the survival analysis was carried out only between the remaining two groups, as the amount of patients in the $\mathrm{R}$ and NSR group were too small to analyze. From the comparison, $\mathrm{S}$ group was not statistically superior to NSR group ( $P=0.2846$,Figure4F).

\section{Discussion}

Pulmonary MALT lymphoma is a rare mature B-cell lymphoma that presents with an indolent clinical course and lacks of specific manifestations in clinical, imaging and laboratory examination, and about one-third of patients are asymptomatic at initial diagnosis ${ }^{[3]}$. Because of its low incidence rate and nonspecific clinical features, It's often confounded with other lung diseases with higher morbidity in China, including lung cancer, pneumonia and tuberculosis, without pathologically confirmation ${ }^{[4]}$. In addition, the specificity of this anatomical site makes it difficult to obtain tumor tissues from pulmonary lesion, and it is frequent that the tissues acquired by transbronchial lung biopsy or computed tomography-guided percutaneous lung puncture are too small to make a definite diagnosis. Therefore, diagnostic biopsy is essential at some cases. Meanwhile, surgical intervention possesses a therapeutic effect for those patients with localized lesions.

So far, only a few prospective small-scale studies on the treatment of pulmonary MALT lymphoma have been reported because of the extremely-low prevalence and fine clinical outcome. In a single-institution, retrospective study of 21 patients with bronchial-associated lymphoid tissue (BALT) MALT lymphomas who were initially managed with combination chemotherapy $(n=7)$, surgery $(n=5)$, observation $(n=4)$, singleagent rituximab $(n=3)$ and radioimmunotherapy $(n=2)$.There were 10 complete remission(CR),3 partial remission(PR),7 stable disease and 1 disease progression in the observation period, and PFS and OS were $90 \%$ and $95 \%$ at 80 months in the study. Besides, additional 326 BALT lymphoma patients recorded in the SEER database were generalized. Treatment modalities such as surgery (alone or with RT and/or chemotherapy), chemotherapy (single agents or combination chemotherapy, alone or with RT and/or surgery), radiotherapy (alone or with chemotherapy and/or surgery), immunotherapy or observation have been assessed and favorable treatment responses and clinical outcomes were observed. Moreover, there were no significant differences in outcomes between patients at different stages ${ }^{[5-10]}$.In another retrospective study of patients with pulmonary MALT lymphoma( $n=51$, Ann Arbor stage IE 76.5\%),compared with advanced-stage disease group, longer PFS (40.7 months vs 24.9 months in median; $P<.001)$ and lower probability of progression (hazard ratio, 9.24) were observed in early-stage pulmonary MALT lymphomas, in which the most common treatment modality was surgical resection $(33 / 43,76.7 \%$ vs $0 / 8,0 \% ; P<.001)$, during 
the follow-up period in a median of 40.7 months. Among the 43 cases of patients with low-stage pulmonary MALT lymphoma,33 of them received complete surgical excision while the rest 10 cases underwent systemic chemotherapy $(n=6)$ or watch and wait $(n=4)$ instead. More patients have achieved complete remission (CR) through surgery resection $(32 / 33,97 \%)$ than those who didn't take surgery resection $(3 / 10,30 \%)$, and the difference of continuous $C R$ rate between the two groups was statistically significant $(P<.001)$. Nevertheless, no statistical differences were found not only in the proportion of patients with disease progression $(1 / 33,3.0 \%$ vs $2 / 10,20.0 \% ; P=0.256)$ but also in $\operatorname{PFS}(P=0.319)$ between the two groups ${ }^{[11]}$. Watch-and-wait policy has also been evaluated in 11 patients who didn't accept immediate treatment after initial diagnosis. Among them, the lesions of 5 patients were restricted to the lungs while the remaining 6 patients with pulmonary MALT lymphoma were found additional extrapulmonary sites when detected for staging. Extensive staging and restaging every three months were taken in all patients. During the long-term followup(28.1 months in median),there were 6 patients experienced spontaneous regressions without any manifestations outside the lung, one patients was received treatment for MALT lymphoma due to disease progression in the lung and 2 cases of extrapulmonary progression were found out. All of these patients were alive and kept in a stable state of disease, and 8 of whom were still only being closely watched. The findings of this retrospective study suggested that watch-and-wait policy was adoptable especially in those who were asymptomatic at diagnosis ${ }^{[12]}$.

Based on the aforesaid small-sample size, single-center studies on pulmonary MALT Iymphoma, in combination with several previous retrospective studies on non-gastric MALT Lymphomas with small sample size of pulmonary MALT lymphoma, different clinical efficacies achieved by ISRT (24-30Gy), surgery, targeted therapy (rituximab), systemic chemotherapy, antibiotics(clarithromycin) and observation, either alone or in combination, were observed ${ }^{[1,2,13-18]}$. Some patients even presented a potential of spontaneous regression within long-term follow up $[12,14,19,20]$. Generally, local therapies such as surgical resection and radiotherapy are widely used for focal lesions, and diffuse lesions are more likely to be treated with systemic immunochemotherapy ${ }^{[9]}$. However, till now, optimal treatment as well as the role of surgery in pulmonary MALT lymphoma still remains controversial[ ${ }^{[21]}$.

In the current study, survival analyses were conducted relied on the data of pulmonary MALT lymphoma patients from SEER database to investigate the value of surgery in treatment. Various treatment combinations of surgery and/or radiation were compared in all patients as well as patients stratified with different age of onset, clinical stages, laterality and primary site of lung. There was not any statistical difference in pulmonary MALT lymphoma patients with unilateral or bilateral sites $(P=0.7279)$,so was in those patients whose primary lesions were in the upper/middle/lower lobe or with overlapping lesion of lung $(P=0.4223)$. The other two indicators, different age of onset $(P<0.0001)$ and clinical stages $(P=$ 0.0638), were further analyzed.

The group of patients that received both surgery and radiation demonstrated its survival superiority, and pairwise comparisons conducted between SR group and the other three groups revealed that, except for $S$ group, differences between R and SR, NSR and SR groups had obvious statistical significance. The remaining three groups were compared pairwise as well, and the $S$ group had a significant advantage of survival over the NSR group while the OS difference between the S and R group was insignificant. 
Statistically, the survival of the S group was neither inferior to the survival of the SR, nor better than the $R$ group, while the OS of R group was not different from NSR group significantly. Possible explanation for the contradiction exhibited by the survival analysis results between $\mathrm{S}$ and $\mathrm{SR}, \mathrm{S}$ and $\mathrm{R}$ groups was that, radiotherapy is a kind of treatment method with relatively excellent short-term efficacy but more pulmonary complications. It may be as effective as surgical resection in a certain period of time. After a long-term follow-up, the efficacy from radiotherapy would lapse and treatment-related side effects gradually emerged while positive results of surgical treatment were continuous. It could be due to the condition that the time span of follow-up was not long enough so that no statistical difference in OS between the $S$ and $R$ group was observed. As for the comparison between R and NSR group, patients undergoing radiotherapy gained therapeutic benefits over a period of time and then it appeared a cliff-like survival reduction on the survival curve, which narrowed the survival difference between the R and NSR group in some degree (Fig. 5A/B). Further investigation into the causes of death among patients who have received radiotherapy(R and $S R)$ or not(S and NSR) revealed that the leading cause of death in patients treated with radiotherapy was pulmonary-related diseases $(6 / 15,40.0 \%)$, including chronic obstructive pulmonary disease $(n=2)$, pneumonia and influenza $(n=1)$ or other lung and bronchus diseases $(n=3)$, and the proportion of patients in R and SR group dying from pulmonary-related diseases was approximately twice that of $S(16 / 101,15.8 \%)$ and NSR(23/131,17.6\%) group. Therefore, it was reasonable to conjecture that lung injury and consequent pulmonary complications induced by radiotherapy were one of the possible reasons for the decline in survival of patients who received radiation therapy.

The above-mentioned results confirmed the effectiveness and sustainability of surgery in the treatment of pulmonary MALT lymphoma. Further subgroup analyses were performed on different ages of onset and clinical stages. Differences among the four treatment groups were statistically significant in the group in which patients were over 60 years old $(P<0.0001)$, especially in $S R$ group $(P=0.0403)$ and $S$ group $(P<$ $0.0001)$ which demonstrated superior to NSR group statistically. For early-stage patients, the survival comparison of the four treatment groups were significant $(P<0.0001)$, especially the $S R$ VS NSR groups $(P=$ $0.0065)$ and $S$ VS NSR groups $(p<0.0001)$, and the SR group indicated a prominent advantage than $R$ group as well $(P=0.0283)$. Besides, In the young group, the four treatment methods didn't show any advantages and disadvantages between each other. The phenomenon, on the one hand, may be attributed to the better physical status and treatment tolerance of the patients in this group, on the other hand, due to the insufficient follow-up time of the current study. The OS of advanced-stage patients (stage III-IV) also weren't different between $S$ group and NSR group.

The 5-year and 10 year cumulative survival rate of the patient population involved in the study were $82.57 \%$ and $73.88 \%$ respectively, which were similar to former reports ${ }^{[5,21]}$. During the period of follow-up, a total of $249(29.0 \%)$ patients died, and the causes of death were classified in this study. Despite of the high survival rate in the patients with pulmonary MALT lymphoma, non-hodgkin lymphoma remained to be the major cause of death $(n=64,25.7 \%)$. Cardiovascular and cerebrovascular diseases were the second leading cause of death, and $47(18.9 \%)$ patients died because of them. Old age of onset may contribute to this phenomenon, as this kind of disease is one of the most common causes of death in the elderly patients originally. Besides, there were 45(18.1\%) pulmonary MALT lymphoma patients died of pulmonary-related diseases. 


\section{Conclusions}

The OS data supported the cognition that pulmonary MALT lymphoma is an indolent disease. And it can be drawn from the comparative research that, the combined therapy of surgery and radiation had clearly manifested its survival advantage in pulmonary MALT lymphoma patients, and surgery itself demonstrated its effectiveness and sustainability in the treatment of those patients, especially stage I-II or elderly patients $(\geq 60)$. To some extent, this study verified the value of surgery among patients with pulmonary MALT lymphoma, which was superior to traditionally-recommended radiotherapy in the persistence of therapeutic effectiveness and less treatment-related complications. And if improved radiotherapy regimens are chosen or the pulmonary complications caused by radiotherapy are well-managed, it's highly possible that to combine radiotherapy with the surgical-based therapy may lead to extra efficacy. Based on the results obtained, we can infer that surgery-based combination therapy may serve as an appropriate first-line treatment recommended for pulmonary MALT lymphoma patients and optimized dose and methods of radiotherapy are needed.

This study is the largest retrospective analysis on pulmonary MALT lymphoma, by far. For the first time, it points out that the survival advantage of the combined treatment option based on surgical treatment in patients with pulmonary MALT lymphoma, especially in those over 60 years old and in the early-stage of the disease. Meanwhile, there are still some limitations of this study. First of all, the number of patients in both $\mathrm{SR}$ and R group were relatively small. Moreover, due to the lack of information on systemic treatment in this data set from SEER, associated contents were not involved in the present study. It was unclear whether these patients had ever been treated with concomitant medication or not, so that the potential impact of systemic drugs can't be ruled out completely.

\section{Abbreviations}

MALT: Mucosa associated lymphoid tissue

SEER: Surveillance, Epidemiology, and End Results

OS: Overall survival

SR: Both Surgery and Radiation

S: Surgery

R: Radiation

NSR : No Surgery Or Radiation

\section{Declarations}

\section{Ethics approval and consent to participate}


Not applicable

\section{Consent for publication}

Not applicable

\section{Availability of data and material}

The datasets used and/or analysed during the current study are available from the SEER database

\section{Competing interests}

The authors declare that they have no competing interests

\section{Funding}

Basic Research Program of Provincial Science and Technology Department (Natural Science Foundation,BK20160099)

\section{Authors' contributions}

Dr. FanLei corresponded to the article. Du Xinyi and Quan Lin analyzed data and wrote the text. The other authors revised the prose. All authors read and approved the final manuscript.

\section{Acknowledgements}

Not applicable

\section{References}

1. Zucca E, Conconi A, Pedrinis E, Cortelazzo S, Motta T, Gospodarowicz MK, Patterson BJ, Ferreri AJ, Ponzoni M, Devizzi L, Giardini R, Pinotti G, Capella C, Zinzani PL, Pileri S, Lopez-Guillermo A, Campo E, Ambrosetti A, Baldini L, Cavalli F. Nongastric marginal zone B-cell lymphoma of mucosa-associated lymphoid tissue. Blood. 2003;101(7):2489-95.

2. Arcaini L, Burcheri S, Rossi A, Passamonti F, Paulli M, Boveri E, Brusamolino E, Orlandi E, Molteni A, Pulsoni A, Cox MC, Orsucci L, Fabbri A, Frezzato M, Voso MT, Zaja F, Montanari F, Pascutto C, Morra E, Cortelazzo S, Lazzarino M. Nongastric marginal-zone B-cell MALT lymphoma: prognostic value of disease dissemination. Oncologist. 2006;11(3):285-91.

3. Nie YZ, Zheng YW, Miyakawa K, Murata S, Zhang RR, Sekine K, Ueno Y, Takebe T, Wakita T, Ryo A, Taniguchi $\mathrm{H}$. Recapitulation of hepatitis $\mathrm{B}$ virus-host interactions in liver organoids from human induced pluripotent stem cells. EBioMedicine. 2018;35:114-23.

4. Yao D, Zhang L, Wu PL, Gu XL, Chen YF, Wang LX, Huang XY. Clinical and misdiagnosed analysis of primary pulmonary lymphoma: a retrospective study. BMC Cancer. 2018;18(1):281.

5. Stefanovic A, Morgensztern D, Fong T, Lossos IS. Pulmonary marginal zone lymphoma: a single centre experience and review of the SEER database. Leuk Lymphoma. 2008;49(7):1311-20.

6. Cordier JF, Chailleux E, Lauque D, Reynaud-Gaubert M, Dietemann-Molard A, Dalphin JC, Blanc-Jouvan F, Loire R. Primary pulmonary lymphomas. A clinical study of 70 cases in nonimmunocompromised patients. Chest. 1993;103(1):201-8. 
7. Kurtin PJ, Myers JL, Adlakha H, Strickler JG, Lohse C, Pankratz VS, Inwards DJ. Pathologic and clinical features of primary pulmonary extranodal marginal zone B-cell lymphoma of MALT type. Am J Surg Pathol. 2001;25(8):997-1008.

8. Zinzani PL, Tani M, Gabriele A, Poletti V, Stefoni V, Alinari L, Musuraca G, Bonifazi F, Pileri S, Tura S, Baccarani M. Extranodal marginal zone B-cell lymphoma of MALT-type of the lung: single-center experience with 12 patients. Leuk Lymphoma. 2003;44(5):821-4.

9. Ahmed S, Kussick SJ, Siddiqui AK, Bhuiya TA, Khan A, Sarewitz S, Steinberg H, Sison CP, Rai KR. Bronchial-associated lymphoid tissue lymphoma: a clinical study of a rare disease. Eur J Cancer. 2004;40(9):1320-6.

10. Graham BB, Mathisen DJ, Mark EJ, Takvorian RW. Primary pulmonary lymphoma. Ann Thorac Surg. 2005;80(4):1248-53.

11. Lee H, Yang B, Nam B, Jeong BH, Shin S, Zo JI, Shim YM, Kwon OJ, Lee KS, Kim H. Treatment outcomes in patients with extranodal marginal zone B-cell lymphoma of the lung. J Thorac Cardiovasc Surg. 2017;154(1):342-9.

12. Troch M, Streubel B, Petkov V, Turetschek K, Chott A, Raderer M. Does MALT lymphoma of the lung require immediate treatment? An analysis of 11 untreated cases with long-term follow-up. Anticancer Res. 2007;27(5b):3633-7.

13. Ishimatsu Y, Mukae H, Matsumoto K, Harada T, Hara A, Hara S, Amenomori M, Fujita H, Sakamoto N, Hayashi T, Kohno S. Two cases with pulmonary mucosa-associated lymphoid tissue lymphoma successfully treated with clarithromycin. Chest. 2010;138(3):730-3.

14. Goda JS, Gospodarowicz M, Pintilie M, Wells W, Hodgson DC, Sun A, Crump M, Tsang RW. Long-term outcome in localized extranodal mucosa-associated lymphoid tissue lymphomas treated with radiotherapy. Cancer. 2010;116(16):3815-24.

15. Conconi A, Martinelli G, Thieblemont C, Ferreri AJ, Devizzi L, Peccatori F, Ponzoni M, Pedrinis E, Dell'Oro S, Pruneri G, Filipazzi V, Dietrich PY, Gianni AM, Coiffier B, Cavalli F, Zucca E. Clinical activity of rituximab in extranodal marginal zone B-cell lymphoma of MALT type. Blood. 2003;102(8):2741-5.

16. Salar A, Domingo-Domenech E, Estany C, Canales MA, Gallardo F, Servitje O, Fraile G, Montalban C. Combination therapy with rituximab and intravenous or oral fludarabine in the first-line, systemic treatment of patients with extranodal marginal zone B-cell lymphoma of the mucosa-associated lymphoid tissue type. Cancer. 2009;115(22):5210-7.

17. Zucca E, Conconi A, Laszlo D, Lopez-Guillermo A, Bouabdallah R, Coiffier B, Sebban C, Jardin F, Vitolo U, Morschhauser F, Pileri SA, Copie-Bergman C, Campo E, Jack A, Floriani I, Johnson P, Martelli M, Cavalli F, Martinelli G, Thieblemont C. Addition of rituximab to chlorambucil produces superior event-free survival in the treatment of patients with extranodal marginal-zone B-cell lymphoma: 5-year analysis of the IELSG-19 Randomized Study. J Clin Oncol. 2013;31(5):565-72.

18. Salar A, Domingo-Domenech E, Panizo C, Nicolas C, Bargay J, Muntanola A, Canales M, Bello JL, Sancho JM, Tomas JF, Rodriguez MJ, Penalver FJ, Grande C, Sanchez-Blanco JJ, Palomera L, Arranz R, Conde E, Garcia M, Garcia JF, Caballero D, Montalban C. First-line response-adapted treatment with the combination of bendamustine and rituximab in patients with mucosa-associated lymphoid tissue 
lymphoma (MALT2008-01): a multicentre, single-arm, phase 2 trial. Lancet Haematol. 2014;1(3):E10411.

19. Kang HS, Lee HY, Kim SJ, Kim SC, Kim YK, Park GS, Lee KY, Jung JI, Kang JY. An Unusual Presentation of Pulmonary Mucosa-Associated Lymphoid Tissue Lymphoma as Diffuse Pulmonary Infiltrates with Spontaneous Regression. Cancer Res Treat. 2015;47(4):943-8.

20. Fukushima K, Hirosako S, Tenjin Y, Mukasa Y, Kojima K, Saeki S, Okamoto S, Ichiyasu H, Fujii K, Kikukawa Y, Kawanaka K, Kohrogi H. Pulmonary Mucosa-associated Lymphoid Tissue Lymphoma with Spontaneous Regression after Computed Tomography-guided Needle Biopsy: A Case Report and Summary of 8 Reported Cases. Intern Med. 2016;55(24):3655-60.

21. Borie R, Wislez M, Thabut G, Antoine M, Rabbat A, Couderc LJ, Monnet I, Nunes H, Blanc FX, Mal H, Bergeron A, Dusser D, Israel-Biet D, Crestani B, Cadranel J. Clinical characteristics and prognostic factors of pulmonary MALT Iymphoma. Eur Respir J. 2009;34(6):1408-16.

\section{Tables}

Table 1A Baseline clinical features among the four treatment groups of pulmonary MALT lymphoma patients

\begin{tabular}{|c|c|c|c|c|c|c|c|c|c|c|c|c|}
\hline \multirow{2}{*}{\multicolumn{3}{|c|}{ Characteristics }} & \multicolumn{2}{|c|}{$\operatorname{ALL}(\mathrm{n}=860)$} & \multicolumn{2}{|c|}{$\begin{array}{l}\text { Both Surgery and } \\
\text { Radiation }(\mathrm{n}=21)\end{array}$} & \multicolumn{2}{|c|}{$\begin{array}{l}\text { Surgery } \\
(n=391)\end{array}$} & \multicolumn{2}{|c|}{$\begin{array}{l}\text { Radiation } \\
(\mathrm{n}=61)\end{array}$} & \multicolumn{2}{|c|}{$\begin{array}{c}\text { No Surgery or } \\
\text { Radiation }(\mathrm{n}=387 \text { ) }\end{array}$} \\
\hline & & & $\begin{array}{l}\text { Median, } \\
\text { (range)/n }\end{array}$ & $\%$ & $\begin{array}{l}\text { Median, } \\
\text { (range)/n }\end{array}$ & $\%$ & $\begin{array}{l}\text { Median, } \\
\text { (range)/n }\end{array}$ & $\%$ & $\begin{array}{c}\text { Median, } \\
\text { (range) } / \mathrm{n} \\
\end{array}$ & $\%$ & $\begin{array}{l}\text { Median, } \\
\text { (range)/n }\end{array}$ & $\%$ \\
\hline \multicolumn{3}{|c|}{ Age, y (range) } & $66(19-93)$ & & $58(40-83)$ & & $64(19-87)$ & & $\begin{array}{l}69(41- \\
91) \\
\end{array}$ & & $\begin{array}{c}67(25- \\
93) \\
\end{array}$ & \\
\hline \multirow[t]{2}{*}{ Gender } & \multicolumn{2}{|c|}{ Male } & 356 & $41.4 \%$ & 9 & $42.9 \%$ & 149 & $38.1 \%$ & 29 & $47.5 \%$ & 169 & $43.7 \%$ \\
\hline & \multicolumn{2}{|c|}{ Female } & 504 & $58.6 \%$ & 12 & $57.1 \%$ & 242 & $61.9 \%$ & 32 & $52.5 \%$ & 218 & $56.3 \%$ \\
\hline \multirow{2}{*}{$\begin{array}{c}\text { Ann } \\
\text { Arbor } \\
\text { Stage } \\
\end{array}$} & \multicolumn{2}{|c|}{ I-II } & 636 & $74.0 \%$ & 19 & $90.5 \%$ & 317 & $81.1 \%$ & 58 & $95.1 \%$ & 242 & $62.5 \%$ \\
\hline & \multicolumn{2}{|c|}{ III-IV } & 224 & $26.0 \%$ & 2 & $9.5 \%$ & 74 & $18.9 \%$ & 3 & $4.9 \%$ & 145 & $37.5 \%$ \\
\hline \multirow{5}{*}{$\begin{array}{c}\text { Primary } \\
\text { Site of } \\
\text { lung }\end{array}$} & \multicolumn{2}{|c|}{ Upper lobe } & 245 & $28.5 \%$ & 8 & $38.1 \%$ & 118 & $30.2 \%$ & 30 & $49.2 \%$ & 89 & $23.0 \%$ \\
\hline & \multicolumn{2}{|c|}{ Middle lobe } & 100 & $11.6 \%$ & 2 & $9.5 \%$ & 54 & $13.8 \%$ & 4 & $6.5 \%$ & 40 & $10.3 \%$ \\
\hline & \multicolumn{2}{|c|}{ Lower lobe } & 256 & $29.8 \%$ & 10 & $47.6 \%$ & 136 & $34.8 \%$ & 20 & $32.8 \%$ & 90 & $23.3 \%$ \\
\hline & \multicolumn{2}{|c|}{$\begin{array}{l}\text { Overlapping lesion of } \\
\text { lung }\end{array}$} & 20 & $2.3 \%$ & 0 & $0.0 \%$ & 9 & $2.3 \%$ & 0 & $0.0 \%$ & 11 & $2.8 \%$ \\
\hline & \multicolumn{2}{|c|}{ Lung, NOS } & 239 & $27.8 \%$ & 1 & $4.8 \%$ & 74 & $18.9 \%$ & 7 & $11.5 \%$ & 157 & $40.6 \%$ \\
\hline \multirow{4}{*}{ Laterality } & \multicolumn{2}{|c|}{ Bilateral Sites } & 138 & $16 \%$ & 0 & $0.0 \%$ & 36 & $9.2 \%$ & 2 & $3.3 \%$ & 100 & $25.8 \%$ \\
\hline & \multirow{3}{*}{$\begin{array}{l}\text { Unilateral } \\
\text { Site }\end{array}$} & Left & 280 & $32.6 \%$ & 12 & $57.1 \%$ & 135 & $34.5 \%$ & 23 & $37.7 \%$ & 110 & $28.4 \%$ \\
\hline & & Right & 439 & $51 \%$ & 9 & $42.9 \%$ & 219 & $56.0 \%$ & 36 & $59.0 \%$ & 175 & $45.2 \%$ \\
\hline & & Unspecified & 3 & $0.4 \%$ & 0 & $0.0 \%$ & 1 & $0.3 \%$ & 0 & $0.0 \%$ & 2 & $0.5 \%$ \\
\hline
\end{tabular}

Table2B Statistical analysis of overall survival, according to treatment;

\begin{tabular}{|c|c|c|c|c|}
\hline Treatment/P value & Both Surgery and Radiation & Surgery & Radiation & No Surgery or Radiation \\
\hline Both Surgery and Radiation & $/$ & 0.1174 & 0.0292 & 0.0116 \\
\hline Surgery & 0.1174 & $/$ & 0.1586 & 0.0001 \\
\hline Radiation & 0.0292 & 0.1586 & $/$ & 0.3833 \\
\hline No Surgery or Radiation & 0.0116 & 0.0001 & 0.3833 & $/$ \\
\hline
\end{tabular}

Table3B The constitution of causes of death among the patients who received radiotherapy; 


\begin{tabular}{|c|c|c|}
\hline Cause of Death & Number & Percentage \\
\hline Pulmonary Disease & 6 & $40.0 \%$ \\
\hline Cardiovascnlar and Cerebrovascular Diseases & 2 & $13.3 \%$ \\
\hline Miscellaneous Malignant Cancer & 2 & $13.3 \%$ \\
\hline Digestive Disease & 2 & $13.3 \%$ \\
\hline Non-Hodgkin Lymphoma & 1 & $6.7 \%$ \\
\hline Other Cause of Death & 1 & $6.7 \%$ \\
\hline Endocrine Diseases & 1 & $6.7 \%$ \\
\hline In Total & 15 & $100.0 \%$ \\
\hline
\end{tabular}

Table 4G Pairwise comparisons between the four treatment methods in subgroups divided according to age and clinical stage;

\begin{tabular}{|c|c|c|c|c|}
\hline \multirow{2}{*}{ Groups/P value } & \multicolumn{2}{|c|}{ Age } & \multicolumn{2}{c|}{ Clinical stage } \\
\cline { 2 - 5 } & $\geq 60$ & $<60$ & Stage I-II & Stage III-IV \\
\hline SR VS S & 0.1695 & 0.6515 & 0.0643 & $/$ \\
\hline SR VS R & 0.1581 & 0.2491 & 0.0283 & $/$ \\
\hline SR VS NSR & 0.0403 & 0.3953 & 0.0065 & $/$ \\
\hline S VS R & 0.4185 & 0.2154 & 0.1938 & $/$ \\
\hline S VS NSR & $<0.0001$ & 0.1700 & $<0.0001$ & 0.2846 \\
\hline R VS NSR & 0.1825 & 0.5998 & 0.3078 & $/$ \\
\hline
\end{tabular}

\section{Figures}

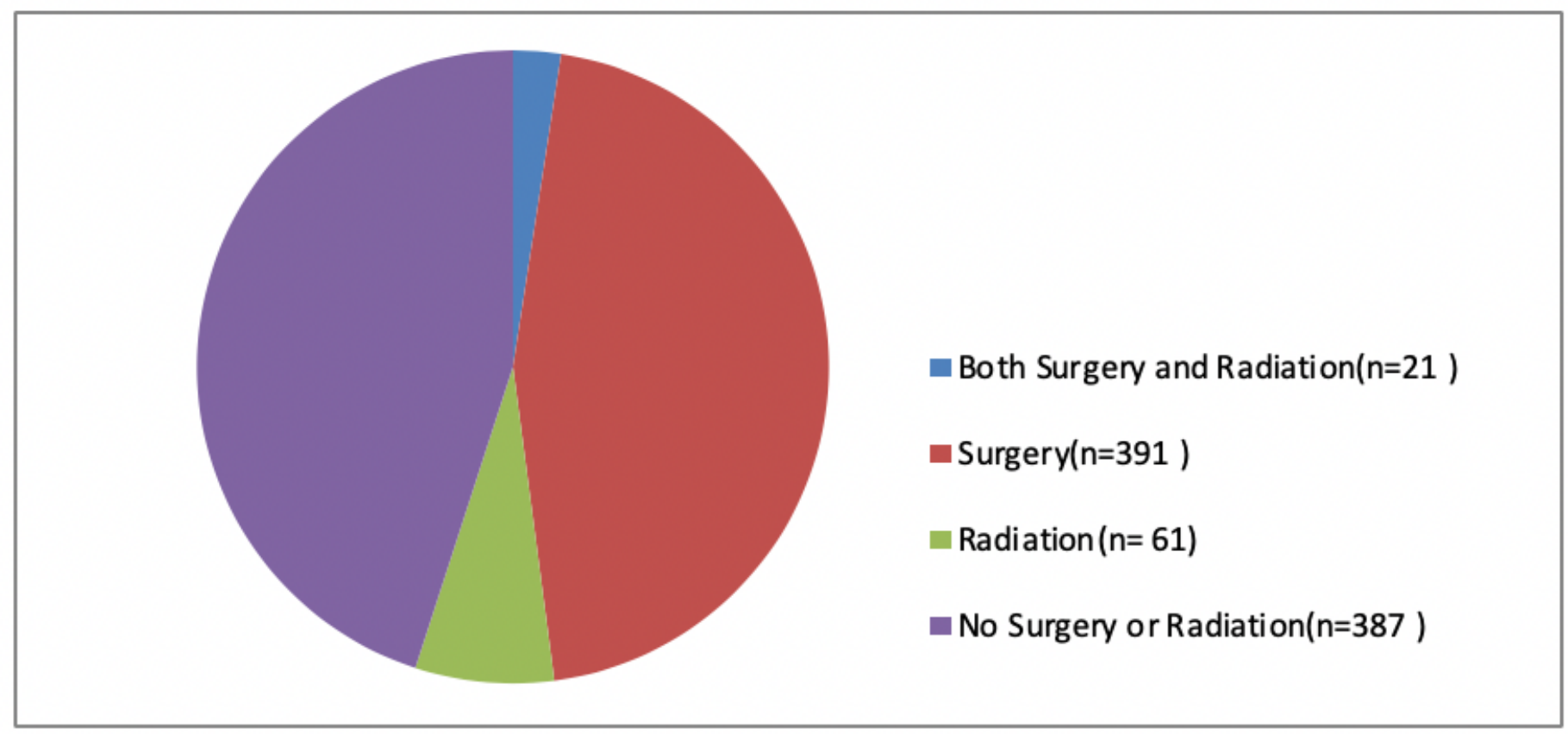

Figure 1

B. Distribution of the four subgroups 


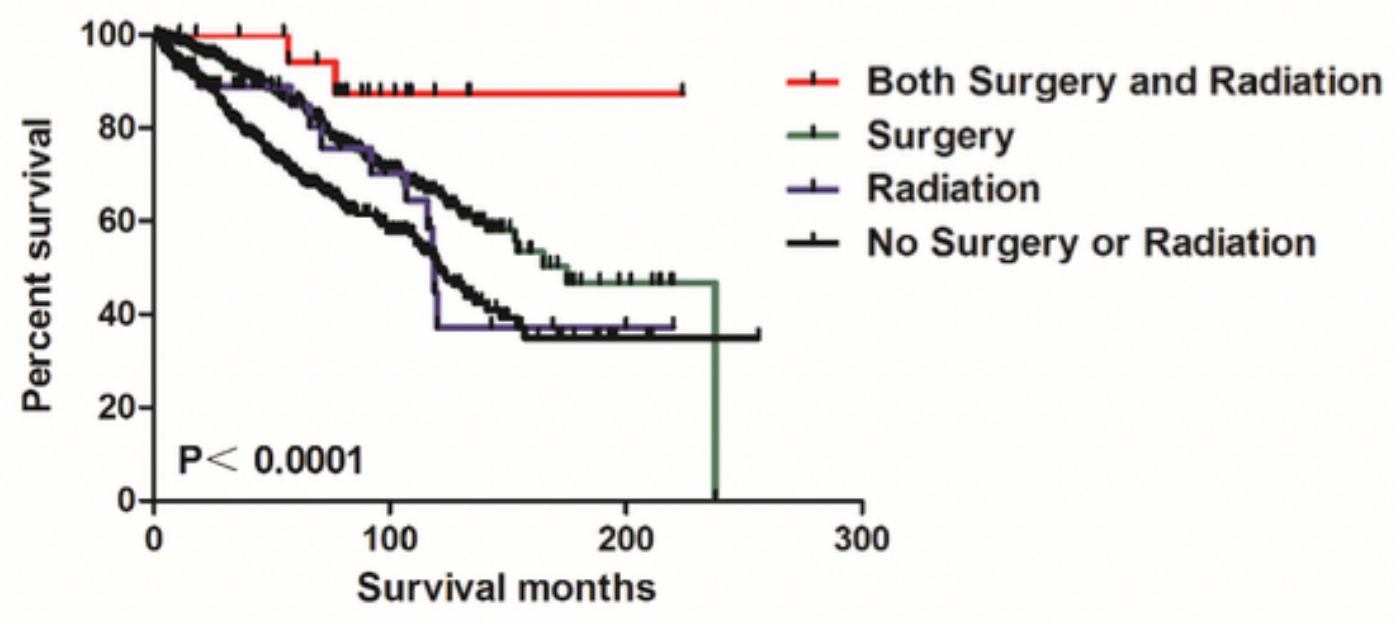

Figure 2

A. Kaplan-Meier actuarial curves of four treatment strategies

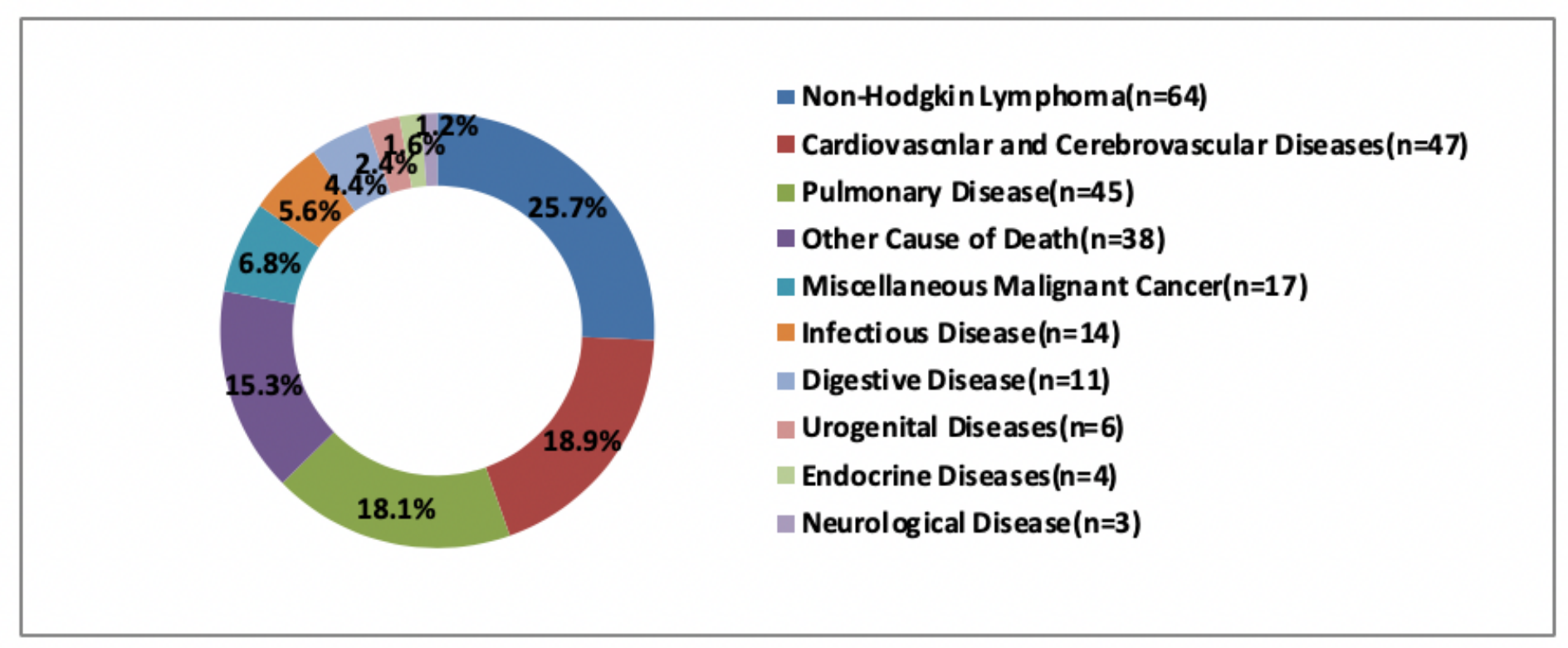

Figure 3

A. Classification of Causes of Death 
Figure4A Age

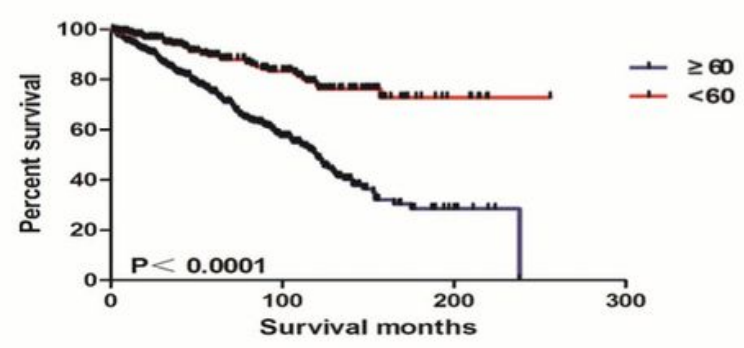

Figure4B $\geqslant 60$

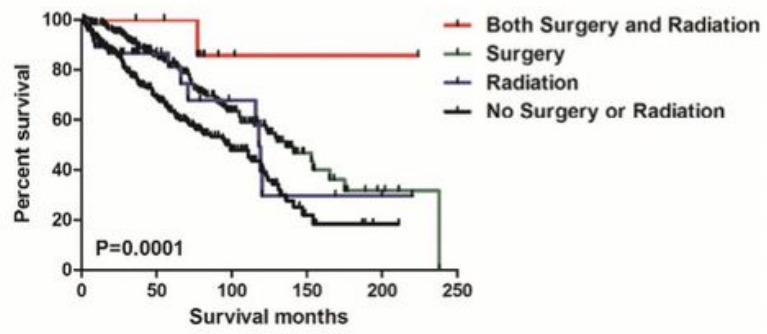

Figure4D Clinical Stage

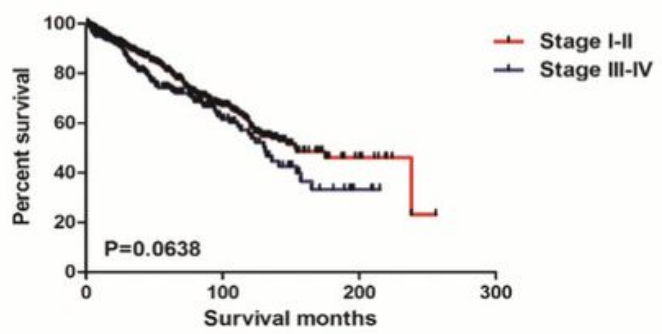

Figure4E Stage I-II

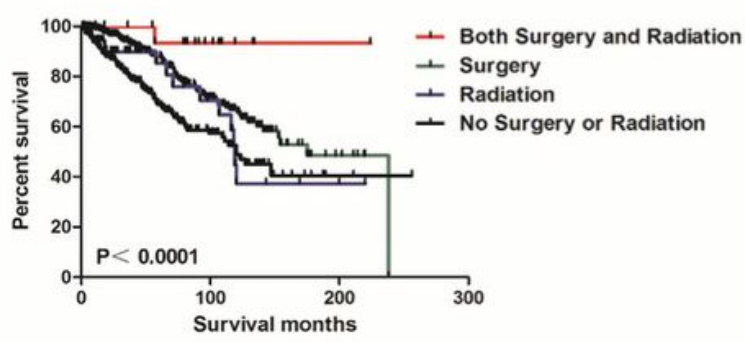

Figure $4 C<60$

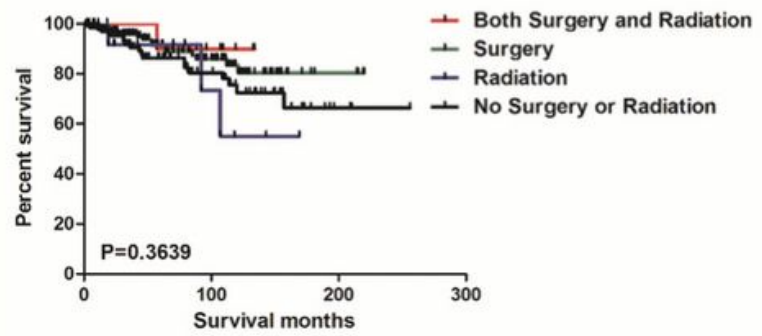

Figure4F Stage III-IV

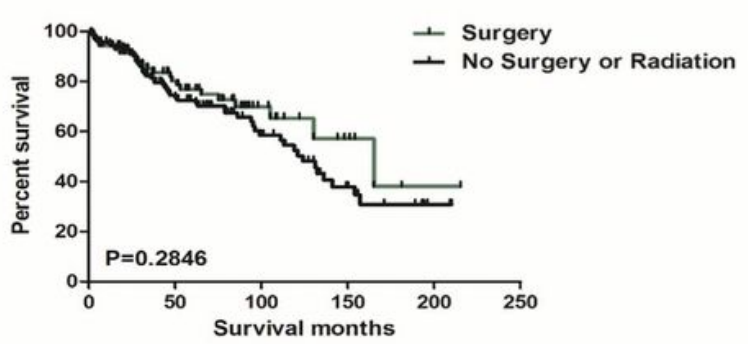

\section{Figure 4}

A. Survival curves by Kaplan-Meier method between two groups of patients aged over or less than 60 years old $\mathbb{B} / \mathrm{C}$. Survival curves of four treatment methods in $\geq 60 /<60$ group $\mathbb{D}$. Survival curves by Kaplan-Meier method between two groups of patients in Stage I-II and III-IV区 E/F. Survival curves of four treatment methods in Stage I-II/III-IV group》 


\section{Figure5A}

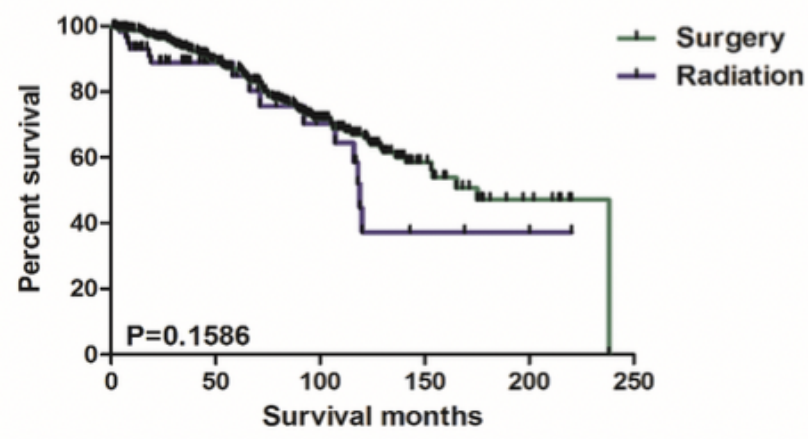

Figure5B

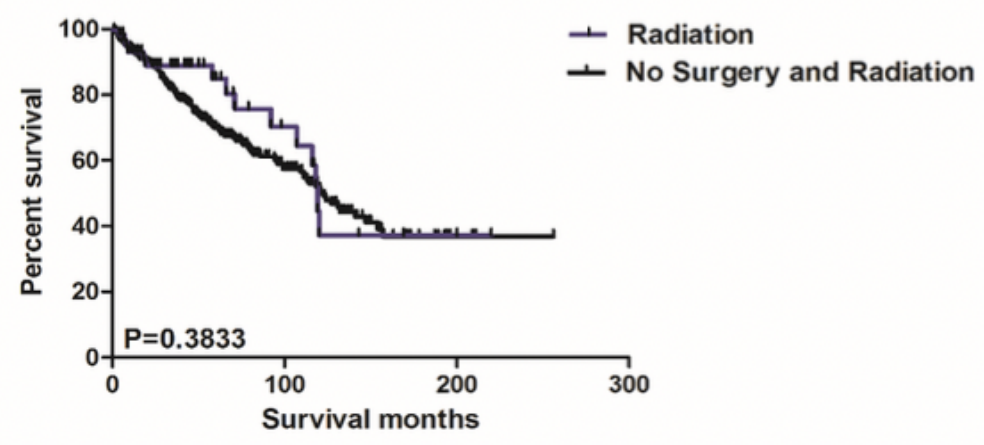

\section{Figure 5}

A/B. Survival curves by Kaplan-Meier method between S and R / R and NSR group. 